\title{
Prucalopride: the evidence for its use in the treatment of chronic constipation
}

\section{Georges Coremans}

Division of Gastroenterology, University Hospital Gasthuisberg, University of Leuven, Leuven, Belgium

\begin{abstract}
Introduction: Chronic constipation is a common condition that is difficult to treat. Existing options for the treatment of patients with different subgroups of constipation are limited. A new efficacious and safe drug is needed to limit the frequently observed adverse effects induced by laxatives, to improve general wellbeing and quality of life, and to provide an alternative for enemas or even resectional surgery in patients in whom stimulant laxatives cause disabling adverse effects or fail to increase bowel movement frequency.
\end{abstract}

Aims: The purpose of this article is to assess the current evidence supporting the use of the selective and high affinity serotonin-4 (5- $\left.\mathrm{HT}{ }_{4}\right)$ receptor agonist prucalopride in the management of chronic constipation.

Evidence review: There are now convincing data from phase II and multicenter phase III randomized, double-blind, placebo-controlled trials that prucalopride treatment results in a clinically meaningful increase in the number of spontaneous complete bowel movements, a reduction of perceived severity of symptoms and improved disease-related quality of life in a significant proportion of patients. There is a rapid onset of the effect and the improvement is maintained for at least 12 weeks.

Prucalopride in a dose of up to $4 \mathrm{mg}$ per day appeared generally well tolerated and devoid of serious cardiac events. Adverse events, most frequently headache and nausea, are usually mild or moderate and occur mainly during the first days of treatment. Prucalopride should be used with prudence and with careful assessment of the benefit-risk ratio until more clinical and electrophysiologic data become available, because relatively few patients have been exposed to the drug for long periods of time.

Place in therapy: Prucalopride 1-2 mg once daily may be given to patients suffering from chronic constipation for whom laxatives do not provide adequate relief of their symptoms. Patients with severe constipation and slow transit, who frequently develop tolerance to stimulant laxatives, are also eligible for prucalopride treatment.

Core Evidence. 2008;3(1):45-54

doi: $10.3355 /$ ce.2008.011

Key words: prucalopride, $5-\mathrm{HT}_{4}$ agonist, chronic constipation, laxatives, bowel movements, safety, tolerance, gastric emptying, small bowel transit, colonic transit

| Core evidence place in therapy summary for prucalopride in chronic constipation

\begin{tabular}{|c|c|c|}
\hline Outcome measure & Evidence & Implications \\
\hline \multicolumn{3}{|l|}{ Patient-oriented evidence } \\
\hline $\begin{array}{l}\text { Statistically significant percentage of patients with increase } \\
\text { of } \geq 1 \text { spontaneous complete bowel movement }\end{array}$ & Clear & Improved symptom control and less need for laxatives \\
\hline $\begin{array}{l}\text { Percentage of patients with } \geq 3 \text { spontaneous complete bowel } \\
\text { movements and relief of constipation }\end{array}$ & Substantial & $\begin{array}{l}\text { Prucalopride can restore normal bowel function in a subgroup of difficult } \\
\text { to treat patients }\end{array}$ \\
\hline $\begin{array}{l}\text { Improvement of perceived severity of constipation and of } \\
\text { constipation-related symptoms }\end{array}$ & Clear & Improved symptom control \\
\hline Maintenance of clinical response & Moderate & Prucalopride may be used long term \\
\hline Significant improvement of disease-specific quality of life & Moderate & $\begin{array}{l}\text { Prucalopride can be considered as first-line treatment in patients in } \\
\text { whom laxatives fail }\end{array}$ \\
\hline Overall treatment satisfaction & Moderate & $\begin{array}{l}\text { Prucalopride can be used as first-line treatment in patients in whom } \\
\text { laxatives fail }\end{array}$ \\
\hline Reduced need for laxatives & Limited & $\begin{array}{l}\text { Additional laxatives may be required in patients with more } \\
\text { severe symptoms }\end{array}$ \\
\hline Efficacy superior to laxatives & No evidence & No controlled comparative trials are available \\
\hline $\begin{array}{l}\text { Efficacy in patients with associated pelvic floor dysfunction } \\
\text { continued overleaf... }\end{array}$ & Limited & Addition of prucalopride to current standard treatment may be useful \\
\hline
\end{tabular}




\begin{tabular}{|c|c|c|}
\hline \multicolumn{3}{|l|}{...table continued } \\
\hline Outcome measure & Evidence & Implications \\
\hline Avoiding enemas or resectional surgery & No evidence & $\begin{array}{l}\text { Controlled trials in the subgroup of patients with most severe signs and } \\
\text { symptoms are awaited }\end{array}$ \\
\hline Absence of severe and cardiovascular adverse effects & Moderate & $\begin{array}{l}\text { A potential advance in the therapy of a population in need of a safe } \\
\text { treatment providing adequate relief }\end{array}$ \\
\hline Mild adverse effect profile & Clear & $\begin{array}{l}\text { Prucalopride can be used as first-line treatment and patients with a } \\
\text { good response are likely to benefit in the long term }\end{array}$ \\
\hline \multicolumn{3}{|l|}{ Disease-oriented evidence } \\
\hline Significant shortening of the time to first stool & Clear & $\begin{array}{l}\text { This finding may be in favor of pulse treatment, side effect } \\
\text { profile permitting }\end{array}$ \\
\hline Significant increase in bowel movements with no straining & Clear & Better symptom control and fewer laxative-induced side effects \\
\hline $\begin{array}{l}\text { Significant increase in bowel movements with } \\
\text { normal consistency }\end{array}$ & Clear & Better symptom control and fewer laxative-induced side effects \\
\hline Significant dose-dependent effect & Clear & $\begin{array}{l}\text { Dose reduction for adverse events does not necessarily compromise } \\
\text { relief of constipation }\end{array}$ \\
\hline $\begin{array}{l}\text { Significant reduction in total colon transit time in patients } \\
\text { with severe constipation }\end{array}$ & Limited & $\begin{array}{l}\text { Patients with more severe symptoms may require combination therapy } \\
\text { with laxatives }\end{array}$ \\
\hline $\begin{array}{l}\text { Significant reduction in oro-cecal transit time and right } \\
\text { colonic emptying }\end{array}$ & Clear & $\begin{array}{l}\text { Prucalopride may also be useful in patients with constipation and } \\
\text { associated upper gastrointestinal motility disorders }\end{array}$ \\
\hline \multicolumn{3}{|l|}{ Economic evidence } \\
\hline $\begin{array}{l}\text { Cost effectiveness compared with stimulant or other } \\
\text { laxatives and pelvic floor retraining }\end{array}$ & No evidence & Long-term pharmacoeconomic studies need to be designed \\
\hline
\end{tabular}

\section{Scope, aims, and objectives}

Although the pathogenesis of both normal and slow transit constipation is incompletely understood, there is plenty of evidence to develop serotonin-4 $\left(5-\mathrm{HT}_{4}\right)$ receptor agonists in the treatment of chronic constipation as they accelerate transit, increase stool frequency, and improve stool consistency (Cash \& Chey 2005).

Prucalopride (Resolor ${ }^{\circledR}$, Movetis) is a selective high affinity 5- $\mathrm{HT}_{4}$ receptor agonist that facilitates cholinergic and excitatory nonadrenergic, noncholinergic neurotransmission (Leclere 2005). The drug is orally active and acts via a systemic mechanism initiating high amplitude propagated contractions (HAPCs) in the colon (De Schryver et al. 2002). It enhances colonic propulsion and accelerates right colon emptying (Emmanuel et al. 1998; Bouras et al. 2001). Prucalopride also accelerates gastric emptying and small bowel transit (Bouras et al. 2001). This review seeks to assess the scientific rationale for using prucalopride in chronic constipation and to discuss the current evidence for its role in the management of chronic constipation.

\section{Methods}

English language literature searches were conducted on June 26, 2008 in the following databases, searching from the beginning of the database to date. The search terms used were "prucalopride", "prucalopride UEGW" or "prucalopride and constipation". The search strategy further included the limits "human, clinical trials, meta-analysis, randomized controlled trial", "clinical trial", or "meeting abstracts".

- PubMed, http://www.ncbi.nlm.nih.gov/entrez/queary.fcgi, 1966 to date
- EMBASE, http://www.datastarweb.com

- National Institute for Health and Clinical Excellence (NICE), http://www.nice.org.uk

- York University Centre for Reviews and Dissemination databases, http://www.crd.york.ac.uk/crdweb/

- Google, www.google.be

Following removal of duplicates, reviews of drug class, treatment options, mechanistic studies in healthy volunteers, and pharmacokinetic studies, a total of six full papers and 11 abstracts were included in the evidence base. A summary of the literature search is presented in Table 1.

\section{Disease overview}

Constipation is a frequent gastrointestinal motility disorder with a prevalence ranging from $3 \%$ to $28 \%$ (Drossman et al. 1993; Talley et al. 1993; Higgins \& Johanson 2004), and affecting mainly women (Johanson 1998). In daily practice constipation is defined on the basis of a combination of symptoms including < 2 bowel movements per week, hard stools, straining, false urge, and the feeling of incomplete emptying. The symptom constellation and underlying pathophysiologic mechanisms may vary considerably among patients (Lembo \& Camilleri 2003). Chronic constipation negatively affects healthrelated quality of life and overall wellbeing, and generates high direct and indirect costs (Sonnenberg \& Koch 1989; Rantis et al. 1997; Martin et al. 2006). It interferes with many aspects of patients' lives, including normal work, and is associated with psychologic morbidity (Damon et al. 2004; Dennison et al. 2005; 
Table 1 | Evidence base included in the review

\begin{tabular}{|lcc|} 
& \multicolumn{2}{c|}{ Number of records } \\
\cline { 2 - 3 } Category & Full papers & Abstracts \\
\hline Initial search & 73 & 13 \\
records excluded & 67 & 4 \\
\multicolumn{1}{c}{ records included } & 6 & 9 \\
Additional studies identified & 0 & 2 \\
Total records included & 6 & 11 \\
Level 1 clinical evidence & 0 & 0 \\
(systematic review, meta analysis) & 6 & 11 \\
Level 2 clinical evidence (RCT) & 0 & 0 \\
Economic evidence & & \\
\hline $\begin{array}{l}\text { For definitions of levels of evidence, see inside back cover or Core Evidence website } \\
\text { (http://www.coremedicalpublishing.com). }\end{array}$ & & \\
RCT, randomized controlled trial. &
\end{tabular}

Legoretta et al. 2006). In most patients with chronic constipation no obvious dietary or structural causes for their symptoms can be demonstrated.

Chronic idiopathic constipation includes normal transit constipation, slow transit constipation, and rectal emptying disturbances with a significant overlap among the subgroups (Velio \& Bassotti 1996; Mertz et al. 1999; Locke et al. 2000). They generate symptoms that are nonspecific.

Patients with normal transit constipation report constipation and associated symptoms of abdominal pain, bloating, or straining in the presence of uncoordinated contractions in the left colon with stool traversing the colon at a normal rate. They often fulfil the criteria of irritable bowel syndrome (IBS) (Crowell 2001). Patients with slow transit constipation have more severe complaints in the presence of delayed transit through the transverse colon that is accompanied by motility disturbances such as reduced HAPCs and the absence of early postprandial contractions (Bassotti et al. 1988; Bazzocchi et al. 1990). The etiology of these motility abnormalities is unclear. Occasionally, patients with more severe constipation also have a generalized gastrointestinal motility disorder (van der Sijp et al. 1993). Rarely, slow transit constipation is associated with colonic inertia not responding to stimulant laxatives (Preston \& LennardJones 1986).

Rectal emptying disturbances, including rectoanal dyssynergia and pelvic floor dysfunction, are characterized by excessive straining, feeling of incomplete evacuation, to application of perineal pressure to assist evacuation or digital evacuation of even soft stools (Lembo et al. 2003).

\section{Role of the neurotransmitter serotonin in the regulation of gut function and constipation}

Serotonin or 5-hydroxytryptamine (5-HT) is a neurotransmitter that plays an important role in a broad range of functions in the gut. Serotonin exerts its effect in the body through a series of receptor subtypes of which the $5-\mathrm{HT}_{3}$ and $5-\mathrm{HT}_{4}$ receptor subtypes are best known in gastrointestinal physiology and physiopathology (Gershon 2004).

Binding of serotonin to $5-\mathrm{HT}_{4}$ receptors stimulates peristalsis, modulates fluid content of the colonic content, and decreases visceral hypersensitivity (Crowell 2001; De Ponti 2004). Patients with slow transit constipation have reduced numbers and function of colonic enterochromografine cells with decreased serotonin activity (El Salhy et al. 1999). It is postulated that this reduced serotonin activity may be associated with the motor and secretory abnormalities described in patients with slow transit constipation. These data make the $5-\mathrm{HT}_{4}$ receptor an attractive mechanistic target for agents that may be useful in the treatment of constipation (Cash \& Chey 2005; Gershon \& Tack 2007).

\section{Current therapy options}

A variety of treatment options have been proposed for patients with chronic constipation, including nonpharmacologic and pharmacologic interventions. However, data on the effectiveness of conservative nonpharmacologic strategies supported by clinical trials are limited (Jones et al. 2002). There is no evidence that increased exercise, fluid intake, and bowel habit training provide relief of all symptoms in patients with chronic constipation (Müller-Lissner et al. 2005). Another conservative nonpharmacologic treatment option, biofeedback retraining of the pelvic floor, has been proposed in well-selected patients with rectoanal dyssynergia. There are now four randomized controlled trials (RCTs) which demonstrate that biofeedback is effective in a subgroup of patients with chronic constipation and the treatment of choice for dyssynergic defecation (Chiarioni et al. 2005, 2006; Heymen et al. 2007; Rao et al. 2007). Meta analysis of studies involving biofeedback compared with other treatments suggested that biofeedback conferred a six-fold increase in the odds of treatment success (Koh et al. 2008). However, additional well-designed studies are also needed that take into account quality of life and psychologic morbidity.

Resectional surgery (subtotal colectomy with ileorectal anastomosis) carries the risk of incapacitating adverse effects and can only be considered in well-selected patients with slow transit constipation associated with colonic inertia not responding to stimulant laxatives and enemas (Coremans 1990; Pemberton et al. 1991).

Orally and rectally administered laxatives adapted to the individual patient are by far the most popular pharmacologic options for patients with chronic constipation. There is good evidence to support the use of osmotic laxatives, more particularly polyethylene glycol (PEG) in patients with chronic constipation. In contrast, there is a paucity of quality data for stimulant laxatives and glycerol (Ramkumar \& Rao 2005) and head-to-head comparison to PEG is not available. But although the benefit of stimulant laxatives has not been supported by comprehensive clinical investigations, clinical experience indicates that laxatives such as bisacodyl, senna, and glycerol, tailored to the individual patient, are generally effective. As a rule, stimulant laxatives are effective in patients with slow transit constipation (Müller-Lissner 
et al. 2005). A significant proportion of patients with chronic constipation are dependent on laxatives to achieve satisfactory bowel functions.

Osmotic laxatives such as nonabsorbed sugars, saline laxatives, and PEG increase intestinal water secretion. They may be used if fibre therapy fails. PEG was found to be more effective than lactulose (Ramkumar \& Rao 2005). The evidence supporting the efficacy of lactulose is only moderate.

The short-term efficacy, tolerance, and safety of the class of osmotic laxatives are best documented for PEG-based laxatives, which have been shown to increase stool frequency and improve stool consistency (Di Palma et al. 2000; Chaussade \& Minic 2003). Obvious limitations of PEG-based laxatives are that only a subgroup of patients with mild chronic constipation respond, lack of effectiveness in providing adequate relief of all symptoms, and that they cause bloating, flatulence, and abdominal cramping eventually necessitating discontinuation of the laxative. There is now convincing evidence to support the efficacy and safety of PEG in the long term (6 months) in adult patients, including elderly patients with chronic constipation (Corazziari et al. 2000; Di Palma et al. 2007).

Stimulant laxatives, both the diphenylmethane and anthraquinone derivates, can be used on a regular basis when osmotic laxatives fail, but their long-term use may be limited by adverse effects, such as severe cramps, eventually necessitating discontinuation of the treatment (Shelton 1980). Tolerance to stimulant laxatives is rare and occurs mainly in the patients with more severe slow transit constipation. In contrast, the need to increase the dose over time is frequently observed (Bengtsson \& Ohlsson 2004). There are, however, no convincing data from pathology studies, performed by using adequate techniques, to support the belief that anthraquinone-containing laxatives may induce damage to the colon and its nerve plexuses (Müller-Lissner et al. 2005).

\section{Unmet needs}

The treatment of patients with normal or delayed colonic transit or outlet obstruction to defecation is nowadays far from always successful. This is particularly the case in the group of patients with more severe slow transit constipation and in patients with neurologic disorders such as Parkinson's disease, multiple sclerosis, and paraplegia. The main effect of laxatives is limited to emptying of the colon. Laxatives rarely provide adequate relief of all the complaints of the patient and frequently induce nausea, bloating, flatulence, distension, abdominal discomfort, and cramping abdominal pain (Müller-Lissner et al. 2005; Di Palma et al. 2007).

Therefore, there is an urgent need for more effective, better tolerated, and safe treatments that normalize bowel function (Di Palma 2005). In patients with impaired colonic propulsive motor activity, a gastrointestinal prokinetic may be a better therapeutic approach (Cash \& Chey 2005). Also, in patients with other types of chronic constipation, including those associated with dyssynergic defecation and pelvic floor dysfunction, it is reasonable to expect that the addition of a promotility agent to current standard treatment options may be useful. Patients with dyssynergic defecation may benefit from biofeedback, which produces greater reductions in symptoms, and the use of enemas and suppositories rather than continuous PEG. In most cases however, some form of laxative treatment will be required, particularly in patients with pelvic floor dyssynergia and slow transit constipation (Chiarioni \& Salandini 2005; Chiarioni et al. 2006). The observation that abnormal serotonin signalling and reuptake appears to play a central role in the symptoms of a subset of patients with chronic constipation provides a rationale for the use of targeted serotonergic agents for the treatment of chronic constipation (Cash \& Chey 2005; De Maeyer et al. 2008). Tegaserod, a selective partial $5-\mathrm{HT}_{4}$ agonist, and to a much lesser extent cisapride, a first-generation promotility agent, were shown to reduce the need for laxatives and provide relief from multiple symptoms of constipation. However, concern about safety due to cardiotoxicity resulted in withdrawal of both promotility agents after they were approved by the FDA (Locke et al. 2000; Altabas et al. 2003; Johanson et al. 2004; Müller-Lissner et al. 2004; Thompson 2007).

\section{Clinical evidence for the use of prucalopride in chronic constipation}

\section{Efficacy}

\section{Phase II trials}

An initial phase II trial comparing prucalopride with placebo dates back to 1994 (Coremans et al. 2003). This pilot study, which included mainly female patients with longstanding chronic constipation not responding adequately to laxatives and referred to a single tertiary referral center in Belgium, yielded promising results. Fifty-three patients were randomized in this placebo-controlled, double-blind trial. It was demonstrated that prucalopride $4 \mathrm{mg}$ once daily for 4 weeks was significantly more effective than placebo in reducing time to first stool $(P=0.071)$, softening stools $(P=0.036)$, and decreasing straining $(P=0.037)$. Prucalopride also had a positive effect on stool frequency, feeling of complete evacuation, and total gut transit time, but the differences were not statistically significant compared with placebo. Mean spontaneous stool frequency increased by 2.34 stools per week after prucalopride and by 1.48 stools per week after placebo, suggesting a strong placebo effect. The mean weekly frequency of laxative intake compared with the run-in period was reduced by $0.73 \pm 0.4$ (mean \pm standard error of the mean) in the prucalopride group and by $0.59 \pm 0.24$ in the placebo group. The difference, however, was not significant. Relief of constipation was experienced by a greater proportion of patients in the prucalopride group (37\%) than in the placebo group (19.2\%), and again, although clinically meaningful, the difference was statistically not significant. Dose reduction for excessive gastrointestinal response did not significantly influence stool frequency, stool consistency, degree of straining, or patients' overall relief of constipation. Total gut transit time showed a decrease of 10.39 hours with prucalopride compared with an increase of 7.45 hours with placebo. However, intergroup difference was not statistically significant, possibly because the mean total gut transit time during run-in was longer in the prucalopride group compared with placebo. 
This initial experience with prucalopride treatment for severe chronic constipation supported further phase II investigations of prucalopride regimens in different forms of chronic constipation. The efficacy was further confirmed in six other phase II trials involving patients with chronic idiopathic constipation and one pilot phase II dose-escalation study in patients with constipation due to spinal cord injury.

Emmanuel et al. (2002) reported on 74 women with chronic constipation stratified into slow and normal transit groups. Each group was randomized to receive $1 \mathrm{mg}$ prucalopride or placebo once daily for 4 weeks. In this single centre, double-blind, placebocontrolled trial conducted in the UK, prucalopride, not placebo, not only increased spontaneous stool frequency $(P=0.008)$ and reduced time to first stool $(P<0.001)$, it also significantly improved disease-specific quality of life. Furthermore, prucalopride significantly reduced oro-cecal transit time and increased rectal sensitivity to distension compared with placebo. Prucalopride also reduced the mean number of retained radioopaque markers in the colon compared with placebo, but only in the subgroup with slow transit $(P=0.069)$.

A subsequent phase II dose-finding study was conducted by Sloots et al. (2002) in the Netherlands, evaluating the effect of prucalopride in a short-term, double-blind, placebo-controlled, crossover study. Twenty-eight patients were randomized to receive prucalopride 1 or $2 \mathrm{mg}$ once daily or placebo. Compared with placebo, prucalopride $1 \mathrm{mg}$ significantly increased the mean number of complete spontaneous stools and all bowel movements per week. It also significantly decreased the percentage of bowel movements with hard stools and straining, and enhanced the urge to defecate. Significant changes in stool frequency, stool consistency, and need to strain were not seen with the $2 \mathrm{mg}$ regimen. This may be explained by a relatively high frequency of bowel movements in this group of patients during placebo treatment. The effect of both 1 and $2 \mathrm{mg}$ prucalopride on mean total colonic transit time was not different from the effect of placebo.

Another phase II dose-finding RCT including 251 patients conducted by Otten et al. (1999) in the Netherlands, confirmed a clear dose-dependent increase $(P=0.026)$ in the number of responders. Patients with chronic constipation (defined as having $\geq 2$ of the following for $\geq 6$ months: $\leq 2$ spontaneous bowel movements per week, for $\geq 25 \%$ of the time, and/or hard stools, and/or straining, and/or a sense of incomplete evacuation) were randomized to prucalopride $0.5,1$, or $2 \mathrm{mg}$ twice daily and treated for a 12-week period. Prucalopride 1 and $2 \mathrm{mg}$ twice daily, but not $0.5 \mathrm{mg}$, significantly increased stool frequency $(P<0.01)$ and significantly decreased severity of constipation $(P<0.02)$. Clinical improvement with the higher doses correlated with a shorter transit time, with a significant time difference in the descending colon $(P<0.05)$, and the effect was maintained after 12 weeks. Time to the first spontaneous stool also significantly decreased with a median time of 22.4 hours for placebo versus 3 hours for the group taking prucalopride $2 \mathrm{mg}$ twice daily.

Similar results were observed by Felt-Bersma and colleagues (1999) in a short-term, multicenter, phase II dose-finding study including 172 patients with chronic constipation also defined according to the Thompson criteria. Prucalopride 0.5 , 1 , or $2 \mathrm{mg}$ administered once daily proportionally increased stool frequency $(P<0.05)$ and decreased the time to the first stool $(P<0.001)$. For patient self-assessment of bowel habit, therapeutic efficacy after 4 weeks of treatment with prucalopride $0.5-2 \mathrm{mg}$ was apparent compared with placebo $(P<0.05)$. Prucalopride also significantly decreased total gut transit time from 49 to 39 hours at $1 \mathrm{mg}$ and from 63 to 54 hours at $2 \mathrm{mg}$ versus placebo.

These encouraging results were largely confirmed by a further phase II dose-finding study $(n=234)$ with once daily doses of prucalopride $0.5-4 \mathrm{mg}$ in the US (Miner et al. 1999). After 4 weeks there was a dose-dependent increase in the frequency of spontaneous complete bowel movements and in the percentage of responders defined as having $\geq 3$ bowel movements per week: $32 \%$ with $2 \mathrm{mg}(P<0.05)$ and $54 \%$ with $4 \mathrm{mg}(P<0.001)$ versus $13 \%$ with placebo. There was also a significant beneficial dose-dependent effect on frequency of straining and stool consistency.

Subsequently, Joslyn et al. (2000) performed a phase II multicenter, double-blind, placebo-controlled, dose-finding study in 303 elderly patients (age 65 years and over) with chronic constipation, defined as $\leq 2$ spontaneous complete bowel movements per week. Patients were randomized to prucalopride 1, 2, or $4 \mathrm{mg}$ once daily, or placebo for 4 weeks. They demonstrated that prucalopride increased the proportion of patients with $\geq 3$ spontaneous complete bowel movements and improved constipated-related symptoms versus placebo, but the differences were not statistically significant. There was a significant increase in the proportion of patients with an increase of $\geq 1$ complete bowel movement per week and an increase in the average change in the number of complete bowel movements with prucalopride.

Prucalopride in a dose of 1 or $2 \mathrm{mg}$ appeared also to have definitive activity in patients with constipation due to spinal cord injury. Krogh et al. (2002) described their experience with 23 patients in a double-blind, placebo-controlled, pilot, phase II dose-escalation study of 4 weeks' duration. Compared with runin, the main measures of constipation severity decreased with prucalopride 1 and $2 \mathrm{mg}$. There was also an increase in average weekly frequency of all bowel movements over 4 weeks within the $2 \mathrm{mg}$ group. The observed patient-reported improved bowel habit was accompanied by a significant reduction in median colon transit time by 38.5 hours [95\% confidence interval $(\mathrm{Cl})$ : $-80,-5]$ within the $2 \mathrm{mg}$ group.

Moulin et al. (2008) performed a phase II, multicenter, doubleblind, placebo-controlled study to evaluate the efficacy and safety of prucalopride in 180 patients with constipation secondary to chronic daily opioid use. Prucalopride treatment improved bowel function and there was a trend toward improved quality of life. Prucalopride was also safe and well tolerated in these patients.

\section{Phase III trials}

Two large, placebo-controlled, multicenter phase III trials to assess the therapeutic potential of prucalopride in severe chronic 
constipation confirm prucalopride's effectiveness and safety (Tack et al. 2007; Camilleri et al. 2008).

In the European multicenter, parallel-group, randomized, doubleblind trial, efficacy was analyzed for 713 patients (90.8\% female). Patients with $<2$ spontaneous complete bowel movements per week with straining, or a sensation of incomplete evacuation, or with hard stools received oral doses of prucalopride 2 or $4 \mathrm{mg}$ once daily or placebo for 12 weeks. Results were similar with both doses, which were significantly different from placebo $(P \leq 0.01)$ at the primary endpoint; the percentage of patients with $\geq 3$ spontaneous complete bowel movements per week averaged over 4 and 12 weeks were $10.4 \%$ and $9.6 \%$ for placebo, $23.7 \%$ and $19.5 \%$ for prucalopride $2 \mathrm{mg}$, and $26.6 \%$ and $23.6 \%$ for prucalopride $4 \mathrm{mg}$, respectively.

Furthermore, the percentage of patients with an increase of 1 or more spontaneous complete bowel movements per week, percentage of bowel movements with normal consistency, percentage of bowel movements with no straining, perceived severity of constipation, and overall score from a validated questionnaire measuring symptoms of constipation, were significantly improved with 2 and $4 \mathrm{mg}$ prucalopride versus placebo averaged over 4 and 12 weeks.

Another placebo-controlled, randomized, parallel-group, phase III, 12-week trial conducted at 38 centers in the US with similar primary and secondary endpoints also showed significant effects (Camilleri et al. 2008). Efficacy was analyzed in 620 patients $(87.9 \%$ female) with $\leq 2$ spontaneous complete bowel movements per week. The responses to 2 and $4 \mathrm{mg}$ doses were similar: $30.9 \%$ of those receiving $2 \mathrm{mg}$ once per day of prucalopride and $28.4 \%$ of those receiving $4 \mathrm{mg}$ once per day had $\geq 3$ spontaneous complete bowel movements, compared with $12.0 \%$ in the placebo group $(P<0.001)$. Furthermore, over 12 weeks $47.3 \%$ of the patients receiving prucalopride $2 \mathrm{mg}$ once per day and $46.6 \%$ of those receiving $4 \mathrm{mg}$ once per day had an increase in the number of spontaneous, complete bowel movements of $\geq 1$ per week, on average, compared with $25.8 \%$ in the placebo group $(P<0.001)$.

In addition, the use of prucalopride 2 or $4 \mathrm{mg}$, as compared with placebo, significantly reduced the use of bisacodyl tablets taken per week $(P<0.001)$. The median time to the first spontaneous, complete bowel movement was also significantly shorter after prucalopride compared with placebo. Furthermore, the percentage of patients quite satisfied or extremely satisfied with treatment efficacy during the 12-week period among the prucalopride 2 and $4 \mathrm{mg}$ dose groups was significantly higher than among the placebo group $33.3 \%$ and $37.7 \%$, respectively versus $17 \%, P<0.001)$.

Van Outryve et al. (2008) performed an open label, phase III, multicenter, long-term follow-up study in patients with chronic constipation. Patients had received treatment with prucalopride 2 or $4 \mathrm{mg}$ for 4 or 12 weeks in a double-blind placebo-controlled study, and were allowed to continue treatment for 24 months. Prucalopride was safe and well tolerated in the long term, and patient satisfaction with bowel function was maintained during the entire treatment period (Van Outryve et al. 2008).

\section{Mechanistic studies}

Prucalopride is known to stimulate gastrointestinal enterokinetic activity in animals in both in-vitro and in-vivo studies (Briejer et al. 2001a,b). It has also enterokinetic effects in healthy volunteers (Emmanuel et al. 1998; Bouras et al. 1999; Poen et al. 1999). This dose-dependent effect, characterized by a significant increase in stool frequency and decrease in stool consistency with a higher percentage of loose/ watery stools, is accompanied by a significant shortening of mean colonic transit time and proximal colonic emptying with prucalopride in doses ranging from 0.5-4 mg once daily (Bouras et al. 1999; Poen et al. 1999). An effect of prucalopride in doses of up to $4 \mathrm{mg}$ on gastric emptying or small bowel transit could not be demonstrated in healthy volunteers (Bouras et al. 1999). In contrast, a physiologic study including 40 patients with chronic functional constipation and no evidence of a rectal evacuation disorder not only demonstrated that prucalopride in a dose of 2 and $4 \mathrm{mg}$ accelerates overall colonic transit and ascending colonic emptying, but also gastric emptying and small bowel transit; the effect appeared to be dose dependent (Bouras et al. 2001). The results of this mechanistic study in patients with idiopathic constipation further suggest the possible usefulness of prucalopride not only in patients with constipation but also in patients with an associated upper or generalized gastrointestinal motility disorder.

\section{Tolerability and safety}

Overall prucalopride in a dose of $1-4 \mathrm{mg}$ once daily was well tolerated, with the frequency of adverse events tending to be dose dependent. Adverse events were mild or moderate in all reported phase II and phase III studies, and disappeared in most patients within the first week of treatment. They included headache and nausea, and, less frequently, an excessive gastrointestinal response with abdominal cramps, diarrhea, and flatulence (FeltBersma et al. 1999; Joslyn et al. 2000; Emmanuel et al. 2002; Coremans et al. 2003; Tack et al. 2007).

Adverse events eventually resulted in discontinuation of prucalopride because of complaints that persisted after dose reduction. In the first phase II trial with the $4 \mathrm{mg}$ regimen, adverse events were mild in two-thirds of the patients and resulted in discontinuation of the prokinetic drug in three out of 37 (8.1\%) (Coremans et al. 2003). In the subsequent phase II trial with the $1 \mathrm{mg}$ regimen, three out of $37(8.1 \%)$ prucalopridetreated patients withdrew from treatment because of adverse events (Emmanuel et al. 2002). Overall, $77 \%$ of the prucaloprideand $60 \%$ of the placebo-treated patients reported one or more adverse events. The frequency of nausea, abdominal pain, and headache occurred at a similar frequency in both treatment groups, whilst diarrhea and flatulence were more common with prucalopride $1 \mathrm{mg}$ once daily. Severe adverse events were reported in similar proportions (36\% for prucalopride versus $34 \%$ for placebo).

In the dose-finding phase II study most adverse events were also mild or moderate in severity (Sloots et al. 2002). Headache, the 
Prucalopride | place in therapy

most frequent adverse event, was more frequently reported by patients receiving prucalopride. Three of the 16 patients $(18.8 \%)$ in the $2 \mathrm{mg}$ group withdrew from treatment because of adverse events, which were predominantly gastrointestinal in nature. In elderly patients prucalopride was generally well tolerated. The most common adverse events were abdominal pain, back pain, headache, nausea, and diarrhea, which also occurred in the placebo group. Krogh et al. (2002) reported moderate-to-severe adverse events in four out of 11 patients with constipation due to spinal cord injury receiving prucalopride $2 \mathrm{mg}$ necessitating discontinuation of treatment in two patients (18.2\%).

Clinically relevant changes in cardiovascular or laboratory parameters were reported in none of the patients treated with prucalopride. Also, the use of prucalopride for longer periods of time (up to 24 months) and in elderly patients did not result in clinically significant changes in laboratory values or vital signs, including cardiovascular parameters (Joslyn et al. 2000; Tack et al. 2007; Van Outryve et al. 2008).

These data were recently confirmed by results of a large 12-week, multicenter, phase III trial conducted in the US (Camilleri et al. 2008). Nausea, vomiting, diarrhea, and headache were reported more frequently by patients receiving prucalopride 2 and $4 \mathrm{mg}$ than those receiving placebo. However, these adverse events were mild or moderate in severity and occurred primarily during the first days of treatment. Transient serious adverse events were reported by only $1.4 \%$ and $3.4 \%$ of the patients receiving prucalopride 2 and $4 \mathrm{mg}$, respectively. Incidences of adverse cardiovascular effects were similar among the three treatment groups and there were no clinically relevant changes in the electrocardiographic variables including corrected QT (QTc F) interval.

Based on the available clinical experience prucalopride, a prokinetic with functional overlap with the $5-\mathrm{HT}_{4}$ receptor agonists cisapride and tegaserod (both of which have been withdrawn from the market due to adverse cardiac events), appears safe. The drug was not associated with adverse ventricular repolarization effects or associated with increased ischemic events (Tack et al. 2007; Camilleri et al. 2008). Electrophysiologic studies with prucalopride on ion-channel currents in isolated cardiac cells showed that the drug had a lower affinity for the cardiac potassium HERG channel than does cisapride, a prokinetic that is associated with a risk of torsade de pointes arrhythmias due to excessive action potential prolongation through HERGchannel inhibition. These studies seem to indicate that although prucalopride blocks HERG channels, a large safety margin at therapeutic concentrations exists (Chapman \& Paternack 2007). Nevertheless, some safety concerns persist and additional data have been requested by some authors (Moss 2008). Taking into account that at the present time relatively few patients have been exposed to prucalopride for longer periods of time, the low rate of occurrence of the life-threatening cardiac side effects related to prolongation of QTC and the lack of more complete electrophysiologic and pharmacologic data warrants a careful assessment of the long-term benefit-risk ratio when prescribing the drug in an individual patient with chronic constipation amenable to prokinetic drug treatment.

\section{Economic evidence}

There are no published data on the assessment of resource utilization with prucalopride treatment or studies providing an economic evaluation of prucalopride in chronic functional constipation.

There appears to be less need for laxatives and thus less cost and adverse events that may interfere with the ability to work in patients successfully treated with prucalopride. However, there are as yet no studies that compare prucalopride and laxatives.

\section{Dosage, administration, and formulations}

Prucalopride is available in oral tablets of $0.5,1,2$, and $4 \mathrm{mg}$. The performed trials provide valuable information on the frequency and timing of prucalopride dosing, but it is clear that their results may need to be adapted to the needs of individual patients. Once daily administration appears to be appropriate and this may be related to the long plasma elimination halflife of prucalopride of approximately 24 hours (Bouras et al. 2001). The fast mode of action of the drug with a maximum concentration of $\sim 3$ hours (Bouras et al. 2001) opens up the possibility of intermittent treatment, but data are currently not available. The effect of prucalopride on stool frequency and constipation-related symptoms is clearly dose related. Prucalopride $2 \mathrm{mg}$ once daily appears to be consistently equally as effective as $4 \mathrm{mg}$ once daily in all published studies. The effect of $1 \mathrm{mg}$ is less consistent and a dose regimen of $0.5 \mathrm{mg}$ once daily proved suboptimal in all studies.

\section{Place in therapy}

Chronic constipation is a common motility disorder that may affect overall wellbeing and quality of life. A subgroup of patients with chronic constipation not only has a delayed colonic transit but also a disordered transit through the upper gastrointestinal tract, associated with symptoms of dyspepsia. Another subgroup has symptoms related to impaired rectal emptying due to pelvic floor dysfunction or rectoanal dyssynergia.

The majority of the currently available treatments for chronic constipation are relatively ineffective, particularly for more severe cases, and have not been tested in well-controlled modern trials. Laxatives remain the most popular treatment for chronic constipation although systematic reviews of these agents do not provide unequivocal evidence that they result in adequate relief of constipation. In daily practice they appear to be generally effective and safe, with no evidence of loss of effect with time in the majority of patients. Tolerance seems to occur mainly in patients with slow transit constipation in whom only stimulant laxatives are effective. A major limitation of chronic treatment with laxatives, however, is that although they increase stool frequency, they do not relieve all the constipation-associated symptoms such as bloating, abdominal discomfort, and pain, resulting in poor compliance. They also may induce troublesome adverse events including flatulence, bloating, and abdominal cramping pain, in itself often associated with chronic constipation. 
Uncovering the role of $5-\mathrm{HT}_{4}$ receptors in the gastrointestinal tract and the development of selective $5-\mathrm{HT}_{4}$ receptor agonists that have clear-cut prokinetic activities offered great opportunities for the treatment of patients with different types of chronic constipation. Specific 5-HT agonists, in contrast to other available drugs that increase intestinal motor activity such as metoclopramide and prostigmine that are poorly tolerated, are an innovative and successful new approach to the treatment of constipation.

Prucalopride is a selective high-affinity $5-\mathrm{HT}_{4}$ receptor agonist that was developed for constipation, and based on available evidence and compared with its predecessors, cisapride and tegaserod, offers improved efficacy and safety to treat patients with severe chronic constipation. This potent, highly selective $5-\mathrm{HT}_{4}$ agonist proved an efficacious, safe, and well-tolerated treatment for the multiple symptoms of chronic constipation. Prucalopride has a rapid onset of enterokinetic activity and increases the number of complete spontaneous bowel movements. Adequate relief of constipation among patients with severe constipation occurs significantly more frequently in patients taking prucalopride compared with placebo. It normalizes bowel function in about $25 \%$ of treated patients and has a beneficial effect on associated symptoms such as hard stools, feeling of incomplete evacuation, and straining. Most importantly, it results in improved sense of general wellbeing and quality of life.

Prucalopride is well tolerated and remained effective in an RCT of up to 12 weeks' duration. The most common adverse events of nausea and headache occurred in the first week of treatment in the majority of patients. Prucalopride also appears to be a safe drug and there is no evidence at the present time that it affects the electrocardiogram or prolongs QTc interval.

A single daily dose appears appropriate. The effects on stool frequency, constipation-associated symptoms as well as adverse effects are dose related. Prucalopride $2 \mathrm{mg}$ once daily appears to be as effective as $4 \mathrm{mg}$ once daily in clinical trials. The effect of $1 \mathrm{mg}$ is less consistent and a dose regimen of $0.5 \mathrm{mg}$ once daily proved suboptimal. The percentages of responders to 2 and $4 \mathrm{mg}$ appear similar. A $2 \mathrm{mg}$ dose regimen appears optimal to start, with dose escalation when needed and dose reduction in the case of adverse events consistent with the prokinetic action that would preclude further treatment with $2 \mathrm{mg}$ once daily.

Prucalopride significantly increases the stool frequency in a clinically significant percentage of patients, but the effect may remain suboptimal in patients with more severe constipation. Prokinetic agents can then be used in combination with other available therapeutic options such as stimulant laxatives, which were used as escape medication in the RCT, or reeducation of the pelvic floor. Taking into account the rapid action of prucalopride, one could also use this colokinetic agent intermittently and not on a daily basis, side effects permitting. Patients with chronic constipation associated with a disordered transit through the upper gut may also benefit from prucalopride as it accelerates not only total colonic transit and ascending colon emptying but also gastric emptying and small bowel transit. Patients with chronic constipation and pelvic floor disorders are traditionally excluded from trials with colokinetic agents to avoid potential error in the evaluation of the therapeutic potential of these agents in patients with chronic constipation that have no evidence of disordered rectal emptying. Taking into account the obvious overlap of different subtypes of constipation, one may speculate that prucalopride, by accelerating oro-cecal and segmental colonic transit and improving stool consistency, may also contribute to better symptom control in patients with constipation and rectal evacuation disturbances. This is in accordance with the reported beneficial effect of prucalopride in patients with paraplegia.

\section{Acknowledgements}

Professor Coremans received honoraria from Janssen Pharmaceutica between 1999 and 2002 for conducting trials with prucalopride. He served on advisory boards for Janssen Pharmaceutica until 2002.

\section{References}

Altabas K, Bilic A, Juricic D, et al. The efficacy of cisapride vs placebo and diet in patient with chronic constipation. Coll Antropol. 2003;27:197-204.

Bassotti G, Gaburri M, Imbimbo B, et al. Colonic mass movements in idiopathic chronic constipation. Gut. 1988;29:1173-1179.

Bazzocchi G, Ellis J, Villanueva-Meyer J, et al. Postprandial colonic transit and motor activity in chronic constipation. Gastroenterology. 1990;98:686-693.

Bengtsson M, Ohlsson B. Retrospective study of long-term treatment with sodium picosulfate. Eur J Gastroenterol Hepatol. 2004;16:433-444.

Bouras EP, Camilleri M, Burton DD, McKinzie S. Selective stimulation of colonic transit by the benzofuran 5-HT4 agonist, prucalopride in healthy humans. Gut.1999;44:482-486.

Bouras EP, Camilleri M, Burton DD, Thomforde G, McKinzie G, Zinsmeister AR Prucalopride accelerates gastrointestinal and colonic transit in patients with constipation. Gastroenterology. 2001;120:354-360.

Briejer MR, Bosmans JP, Van Daele P, et al. The in vitro pharmacological profile of prucalopride, a novel enterokinetic compound. Eur J Pharmacol. 2001a;423:71-83.

Briejer MR, Prins NH, Schuurkes JA. Effects of the enterokinetic prucalopride (R093877) a colonic motility in the fasted dogs. Neurogastroenterol Motil. 2001b;13:465-472.

Camilleri M, Kerstens R, Ryckx A, Vandeplassche L. A placebo-controlled trial of prucalopride for severe chronic constipation. N Engl J Med. 2008;358:23442354.

Cash BD, Chey WD. Review article: the role of serotonergic agents in the treatment of patients with primary chronic constipation. Aliment Pharmacol Ther. 2005;22:1047-1060.

Chapman $\mathrm{H}$, Pasternack $\mathrm{M}$. The action of the novel gastrointestinal prokinetic prucalopride on the HERG K+ channel and the common T897 polymorph. Eur J Pharmacol. 2007;554:98-105

Chaussade S, Minic M. Comparison of efficacy and safety of two doses different polyethylene glycol-based laxatives in the treatment of constipation. Aliment Pharmacol Ther. 2003;17:165-172.

Chiarioni G, Salandini L, Whitehead WE. Biofeedback benefits only patients with outlet dysfunction, not patients with isolated slow transit constipation. Gastroenterology. 2005;129:86-97.

Chiarioni G, Whitehead WE, Pezza V, Morelli A, Bassotti G. Biofeedback is superior to laxatives for normal transit constipation due to pelvic floor dyssynergia. Gastroenterology. 2006;130:657-664.

Coremans GE. Surgical aspects of severe chronic non-Hirschsprung constipation. Hepatogastroenterology. 1990;37:588-595. 
Coremans G, Kerstens R, De Pauw M, Stevens M. Prucalopride is effective in patients with severe chronic constipation in whom laxatives fail to provide adequate relief. Results of a double-blind, placebo-controlled clinical trial. Digestion. 2003;67:82-89.

Corazziari E, Badiali D, Bazzocchi G, et al. Long term efficacy, safety, and tolerability of low daily doses of isosmotic polyethylene glycol electrolyte balanced solution (PMF-100) in the treatment of functional chronic constipation. Gut. 2000;46:522-526.

Crowell MD. The role of serotonin in the pathophysiology of irritable bowel syndrome. Am J Manag Care. 2001;7:S252-S260.

Damon H, Dumas P, Mion F. Impact of anal incontinence and chronic constipation on quality of life. Gastroenterol Clin Biol. 2004;28:16-20.

De Maeyer JH, Lefebvre RA, Schuurkes JA. 5-HT, receptor agonists: similar but not the same. Neurogastroenterol Mol. 2008;20:99-112.

Dennisson C, Prasad M, Lloyd A, Bhattacharyya SK, Dhawan R, Coyne $\mathrm{K}$. The health-related quality of life and economic burden of constipation. PharmacoEconomics. 2005;23:461-476.

De Ponti F. Pharmacology of serotonin: what a clinician should know. Gut 2004;53:1520-1535.

De Schryver AM, Andriesse GI, Samsom M, Smout AJ, Gooszen HG Akkermans LM. The effects of the specific $5 \mathrm{HT}(4)$ receptor agonist, prucalopride, on colonic motility in healthy volunteers. Aliment Pharmacol Ther. 2002;16:603-612.

Di Palma JA, De Ridder PA, Orlando RC, Kolts BE, Cleveland MVB. A randomized placebo-controlled multicenter study of the safety and efficacy of a new polyethylene glycol laxative. Am J Gastroenterol. 2000;95:446-450.

Di Palma JA. Expert commentary - new developments in the treatment of constipation. Med Gen Med. 2005;7:17.

Di Palma JA, Cleveland MV, McGowan J, Herrera JL. A randomized, multicenter, placebo-controlled trial of polyethylene glycol laxative for chronic treatment of chronic constipation. Am J Gastroenterol. 2007;102:1436-1441.

Drossman DA, Li Z, Andruzzi E, et al. US householder survey of functiona gastrointestinal disorders. Prevalence, sociodemography, and health impact. Dig Dis Sci. 1993;38:1569-1580.

El Salhy M, Norrgard O, Spinell S. Abnormal colonic endocrine cells in patients with chronic idiopathic slow transit constipation. Scand J Gastroenterol. 1999;34:1007-1011.

Emmanuel AV, Kamm MA, Roy AJ, et al. Effect of a novel prokinetic drug R093877 on gastrointestinal transit in healthy volunteers. Gut. 1998;42:511516

Emmanuel AV, Roy AJ, Nicholls TJ, Kamm MA. Prucalopride, a systemic enterokinetic, for the treatment of constipation. Aliment Pharmacol Ther. 2002;16:1347-1356.

Felt-Bersma RJF, Bouchacha M, Wurzer H, Van Outryve M, Bosschert H, Van 't Klooster G. Effects of a new enterokinetic drug, prucalopride, on symptoms of patients with chronic constipation. A double-blind, placebo-controlled, multicenter study in Europe. Gastroenterology. 1999;116:A992 (Abstract).

Gershon MD. Review article: serotonin receptors and transporters - roles in normal and abnormal gastrointestinal motility. Aliment Pharmacol Ther. 2004;20(Suppl. 7):3-14.

Gershon MD, Tack J. The serotonin signalling system: from basic understanding to drug development for functional Gl disorders. Gastroenterology. 2007;132:397-414.

Heymen S, Scarlett Y, Jones K, Ringel Y, Drossman D, Whitehead WE. Randomized, controlled trial shows biofeedback to be superior to alternative treatments for patients with pelvic floor dyssynergia-type constipation. Dis Colon Rectum. 2007;50:428-441.

Higgins PD, Johanson JF. Epidermiology of constipation in North America: a systemic review. Am J Gastroenterol. 2004;99:750-759.

Jones MP, Talley NJ, Nuyts G, et al. Lack of objective evidence of efficacy of laxatives in chronic constipation. Dig Dis Sci. 2002;47:2222-2230.

Johanson JF. Geographic distribution of constipation in United States. Am J Gastroenterol. 1998;93:188-191.
Johanson JF, Wald A, Tougas G, et al. Effect of tegaserod in chronic constipation: randomized, double-blind controlled trial. Clin Gastroenterol Hepatol. 2004;2:796-805.

Joslyn A, Stevens M, De Pauw M, Kerstens R. Prucalopride is safe and generally well tolerated in elderly patients with chronic constipation. Am J Gastroenterol. 2000;95:2537-2538 (Abstract).

Koh CE, Young CJ, Young JM, Solomon MJ. Systematic review of randomized controlled trials of the effectiveness of biofeedback for pelvic floor dysfunction. Br J Surg. 2008;95:1079-1087.

Krogh K, Jensen MB, Gandrup P, et al. Efficacy and tolerability of prucalopride in patients with constipation due to spinal cord injury. Scand J Gastroenterol. 2002;37:431-436.

Leclere PG, Prins HH, Schuurkes JAJ, Lefebvre RA. 5-HT, receptors located on cholinergic nerves in human colon circular muscle. Neurogastroentero Motil. 2005; 17:366-375.

Legoretta A, Clark S, Marehbian J, et al. Symptoms associated with chronic gastrointestinal disorders interfere with daily living as assessed by patient reported outcomes in the primary care setting. Am J Gastroenterol. 2006;101:S490 (Abstract).

Lembo A, Camilleri M. Chronic constipation. N Engl J Med. 2003;349:13601368

Locke GR 3rd, Pemberton JH, Phillips SF. AGA technical review on constipation. American Gastroenterological Association. Gastroenterology. 2000;119:1766-1778.

Martin BC, Barghout V, Cerulli A. Direct medical costs of constipation in the United States. Managed Care Interface. 2006;16:43-39.

Mertz H, Naliboff B, Mayer E. Physiology of refractory chronic constipation. Am J Gastroenterol. 1999;94:609-615.

Miner PhB Jr, Nichols T Jr, Silvers DR, Joselyn A, Woods M. The efficacy and safety of prucalopride in patients with chronic constipation. Gastroenterology. 1999;116:A-1043 (Abstract).

Moss AJ. The long and short of a constipation-reducing medication. N Engl J Med. 2008;358:2402-2403.

Moulin DE, Rykx A, Kerstens R, Vandeplassche L. Randomized, doubleblind placebo-controlled trial to evaluate efficacy and safety of prucalopride $\left(\right.$ Resolor $\left.^{\circledR}\right)$ in patients with opioid-induced constipation. Gastroenterology. 2008;134:A-92 (Abstract).

Müller-Lissner S, Kamm M, Haeck P, et al. Long-term safety and tolerability of tegaserod in chronic constipation. Gastroenterology. 2004;126:A602 (Abstract).

Müller-Lissner SA, Kamm M, Scarpignato C, Wald A. Myths and misconceptions about chronic constipation. J Gastroenterol. 2005;100:232242.

Otten $\mathrm{MH}$, Schneider $\mathrm{H}$, Wurzer $\mathrm{H}$, et al. A double-blind, placebo-controlled evaluation of safety and efficacy of 12-weeks, twice-daily treatment with prucalopride in patients with chronic constipation. Gastroenterology. 1999;116:A1055 (Abstract)

Pemberton JH, Roth DM, Ilstrup DM. Evaluation and surgical treatment of severe chronic constipation. Ann Surg. 1991;214:403-411

Poen AC, Felt-Bersma RJF, Van Dongen PAM, Meuwissen SGM. Effect of prucalopride, a new enterokinetic agent, on gastrointestinal transit and anorectal function in healthy volunteers. Aliment Pharmacol Ther. 1999;13:1493-1497.

Preston DM, Lennard-Jones JE. Severe chronic constipation of young women: idiopathic slow transit constipation. Gut. 1986;27:41-48.

Ramkumar D, Rao SSC. Efficacy and safety of traditional medical therapies fo chronic constipation: systemic review. Am J Gastroenterol. 2005;100:936-971.

Rantis PC Jr, Vernava AM 3rd, Daniel GL, Longo WE. Chronic constipation - is the work-up worth the cost? Dis Colon Rectum. 1997;40:280-286.

Rao SS, Seaton K, Miller M, et al. Randomized controlled trial of biofeedback, sham feedback, and standard therapy for dyssynergic defection. Clin Gastroenterol Hepatol. 2007;5:331-338.

Shelton MG. Standardized senna in the management of constipation in the puerperium. A clinical trial. S Afr Med J. 1980;57:78-80. 
Prucalopride | place in therapy

Sloots CE, Poen AC, Kerstens R, et al. Effects of prucalopride on colonic transit, anorectal function and bowel habits in patients with chronic constipation. Aliment Pharmacol Ther. 2002;16:759-767.

Sonnenberg A, Koch TR. Physician visits in the United States for constipation: 1958-1986. Dig Dis Sci. 1989;34:601-611.

Tack J, Tan G, Vandeplassche L. A randomized, double-blind, placebocontrolled trial to evaluate efficacy and safety of prucalopride in patients with chronic constipation. Gut. 2007;56:A46 (Abstract).

Talley NJ, Weaver AL, Zinsmeister AR, Melton L. Functional constipation and outlet delay: a population-based study. Gastroenterology. 1993;105:781-790.

Thompson CA. Novartis suspends tegaserod sales at FDA's request. Am J Health Syst Pharm. 2007;64:1020.

van der Sijp JRM, Kamm MA, Nightingale JMD, et al. Disturbed gastric and small bowel transit in severe idiopathic constipation. Dig Dis Sci. 1993;38:837844.
Van Outryve MJ, Beyens G, Kerstens R, Vandeplassche L. Long-term follow-up study of oral prucalopride $\left(\right.$ Resolor $\left.{ }^{\circledR}\right)$ administered to patients with chronic constipation. Gastroenterology. 2008;134:A-547(T1400).

Velio P, Bassotti G. Chronic idiopathic constipation: pathophysiology and treatment. J. Clin Gastroenterol. 1996;22:190-196.

Correspondence: Professor Georges Coremans, Division of Gastroenterology, University Hospital Gasthuisberg, University of Leuven, Herestraat 49, B-3000 Leuven, Belgium or at georges.coremans@uz.kuleuven.ac.be 